\title{
Of nouns, and kinds, and properties, and why one $D$ is null or not
}

\author{
DIANA GUILLEMIN \\ Griffith University, Australia
}

\section{INTRODUCTION}

The aim of this paper is to investigate the diverse means of quantification that languages use to establish the referential properties of noun phrases through an analysis of how definiteness and specificity are marked across three languages with different determiner (D) systems, namely, English, French, and Mauritian Creole (MC). English and French overtly mark a [ \pm definite] contrast, while MC marks a [ \pm specific] contrast, and this difference is correlated with their different article systems, which is in turn a consequence of the basic denotation of their nouns. Nouns can denote kinds or properties, and natural language makes available typeshifting operators that can shift their denotation from kinds to predicates and generalized quantifiers (GQs) and vice versa (Partee 1986, Chierchia 1998). Operators that are internal to the noun phrase include, among others, articles, numerals, and other quantifiers, and operators that are external to the noun phrase include the existential quantifier, auxiliaries, and tense operators, as well as the predicate that noun phrases combine with. Following Partee (1992), the former will be referred to as D-Quantification and the latter as A-Quantification. I provide a Derivation-by-Phase analysis within a Minimalist syntax framework (Chomsky 1995, 2001a,b) and show that the MC specificity marker is a morphosyntactic element whose function is to license a phonologically null definite article in specific syntactic environments.

My inquiry is motivated by Longobardi's (1994:628) proposal that "DP can be an argument, NP cannot, though D can be a phonologically null element", and Himmelmann's (2001:832) similar claim that "count nouns cannot be used in core argument positions without a marker for definiteness or specificity". These claims are contra Chierchia's (1998) theory that a bare noun $(\mathrm{N})$ can function as an argument when it is kind denoting. Chierchia posits a Nominal Mapping Parameter (NMP), which stipulates that cross-linguistic variation in the denotation of nouns with respect to the features argumental and predicative [ \pm arg, \pm pred] can account for the different distribution and interpretation of bare nominal arguments. Languages whose nouns are specified as [+arg, -pred] (Chinese, Japanese) admit 
bare nouns in argument positions, and languages whose nouns are specified as [-arg, +pred] (Romance) disallow bare nominal arguments (Chierchia 1998:355). According to Chierchia, English has a mixed system, where nouns can be [ \pm arg, \pm pred]: abstract nouns, mass nouns, and plural count nouns can occur in argument positions without a determiner, but not so singular count nouns (Fame is elusive, Water is wet, Birds sing, *Bird sings).

The paper is organised as follows: Section 2 provides background information about the distribution of bare nouns in English, French, and MC. In Section 3, I provide semantic definitions of definiteness and specificity to support my claim that these are distinct semantic categories. Section 4 comprises an overview of the Minimalist assumptions used for the syntactic analysis, including the structure of DP and the Derivation-by-Phase analysis. I also explain how semantic categories are mapped onto syntactic structure within a categorial grammar framework. Section 5 introduces an analysis of how D-Quantifiers and A-Quantifiers type-shift kinds and predicates into GQs, and how number, definiteness, and specificity are marked in the process. Section 6 concludes the paper.

\section{BARE NOUNS IN ENGLISH, FRENCH, AND MC}

Carlson (1978) is in agreement with Chierchia (1998) that English bare plurals (BPs) are strictly bare: that is, there is no evidence of a phonologically null definite article that has quantified over the noun. English BPs can function as arguments without $\mathrm{D}$ because they are argumental, kind-denoting terms that pattern like proper nouns in the grammar. Building on Carlson's (1978) and Chierchia's theories, I have argued (Guillemin 2011) that a strong [+arg] feature enables a noun to raise into a $\mathrm{D}$ position in a move analogous to that of verb (V) raising to inflection (INFL), where movement is triggered by a strong AGREE feature of V. Hence, English BPs in argument positions are $\mathrm{N}$ in $\mathrm{D}$, which are universally quantified noun phrases, that is, DPs, not NPs. Since English abstract nouns and mass nouns can also function as arguments without $\mathrm{D}$, they too are assumed to be specified for a strong [+arg] feature that enables them to raise into a D position.

In French, only some proper nouns, such as personal names (Pierre, Natalie) and names of cities (Lyon, Toulouse), can function as arguments without D. Longobardi $(1994,2001)$ attributes this to the fact that they are inherently referential. French is otherwise very restrictive with respect to the occurrence of bare nominal arguments, and many other proper nouns require an article, such as the names of countries, mountains, and rivers (la France, les Pyrénées, le Rhône). ${ }^{1}$

Turning now to $\mathrm{MC}$, we note that, despite being a French lexifier creole, $\mathrm{MC}$ freely admits bare nominal arguments, which can be [ \pm definite], $[ \pm$ specific $]$, or generic, and in the case of count nouns, singular or plural. Their meaning is simply derived from the context. In example (1), the individual-level predicate selects a kind-denoting noun as subject, while the stage-level predicate in (2) selects

\footnotetext{
${ }^{1}$ Exceptions include fused expressions, such as proverbs, for example Pierre qui roule n'amasse pas mousse.
} 
instances of the kind. The MC bare noun sat 'cat' in (1) translates into an English $\mathrm{BP}$, while French requires a definite article in generic contexts. In (2) sat 'cat' is singular, definite, and specific, and both English and French require a definite article. Nouns in $\mathrm{MC}$ do not inflect for number (as in English and French) or gender (as in French).

(1) Sat ena lapat. generic (universally quantified [-specific]) (MC) cat have paw

'Cats have paws.'

'Le chat a des pattes.'

(French)

(2) Sat malad. [+definite $][+$ specific $]$ singular

cat sick

'The cat is sick.'

'Le chat est malade.'

(French)

Unlike English and French, MC lacks a copula equivalent to auxiliary 'be' (Fr. être), and in non-verbal predicative constructions such as (2), subject and predicate are string-adjacent. The stage-level predicate forces a singular interpretation of the bare noun sat, and both English and French require a definite article. For a plural definite interpretation of the subject of a stage-level predicate in $\mathrm{MC}$, the noun must be marked by the plural marker bann. Bann sat in (3) refers to a set of cats known to all speech participants.

(3) Bann sat malad.

$[+$ definite $][+$ specific $]$ plural

PL cat sick

'The cats are sick.'

'Les chats sont malades.'

(French)

In object position, however, a bare noun in $\mathrm{MC}$ can be [+definite] [+specific] singular, or [-definite] [-specific] plural. The former interpretation is derived if sat in (4) refers to an individual that is unique in the world of discourse, for example, a household pet known to all speech participants, and the common noun patterns like a proper noun. The bare noun sat in (4) can also denote cats in general.

(4) Li gard sat. $\quad[ \pm$ definite $][ \pm$ specific $]$

3SG keep cat

'She keeps cats/the cat.'

'Elle garde des chats/le chat.'

(French)

While a bare noun in object position can be ambiguous as in (4), a bare common count noun that is the subject of a stage-level predicate can only refer to a unique individual, and all common nouns that have a unique denotation in $\mathrm{MC}$ pattern like proper nouns in that they do not require a determiner in argument positions (unlike English and French), as shown in (5). 
(5) Later turn otour soley.

(MC)

earth revolve around sun

'The earth revolves around the sun.'

'La terre tourne autour du soleil.'

(French)

When a common count noun in $\mathrm{MC}$ does not have a unique denotation, the specificity marker $l a$ is required in subject position for a definite singular interpretation, as with Zako in (6). Note, however, that $l a$ is not required with the nouns in object position-both pye and lamontagn, which are the complements of prepositions (lor and depi, respectively) can yield definite interpretations without the specificity marker.

(6) Ena enn zako lor pye. Zako la sort depi lamontagn. (MC) have a monkey on tree monkey SP come from mountain

'There's a monkey on the tree. The monkey comes from the mountain.'

'Il y a un singe sur l'arbre. Le singe vient de la montagne.'

(French)

The specificity marker la forces a singular definite interpretation of the bare common noun. If $l a$ is left out, the subject would yield a generic or habitual reading as shown:

(7) Zako sort depi lamontagn. monkey come from mountain

'Monkeys come from mountains/the mountain.'

'Les singes viennent de la montagne.'

(French)

MC common count nouns that do not have a unique denotation pattern like English singular count nouns, which are the only ones that cannot function as arguments without D. I propose that MC has a phonologically null definite article that performs an identical function to English the. It is an empty category (ec), which requires licensing in certain syntactic environments (Rizzi's 1990, 1997 Empty Category Principle). In internal argument positions, this ec can be licensed by an overt verb or preposition, but there is no governing head in subject position. Subject-object asymmetry of count nouns in MC provides evidence for this null category, as does the occurrence of the specificity marker la, which is a morphosyntactic requirement to license the null definite article in some syntactic environments (Guillemin 2011, 2014).

Given that MC nouns can function as bare arguments, I assume that they are specified as [+arg, - pred], as in Chinese and Japanese. However, unlike these Asian languages, MC makes the count-mass distinction as in English and French, and these different categories of nouns will be shown to pattern differently in the grammar of MC. While common count nouns cannot occur without a D in subject position (unless they have a unique denotation), abstract nouns, mass nouns, and proper nouns can function as bare nominal arguments in any syntactic position with

\footnotetext{
${ }^{2}$ Where $d u$ is the contracted form of the preposition $d e$ and the masculine singular definite article le.
} 
$[ \pm$ definite $][ \pm$ specific $]$ or generic interpretations, and the meaning is derived from the context as shown in (8) to (11). Note that French always requires an article, and English requires an article only when the noun phrase is definite.

(8) Diven uver lapeti. wine open appetite generic $[-$ specific $]$

'Wine stimulates the appetite.'

'Le vin ouvre l'appétit.'

(9) Zot 'nn bwar diven.

3PL ASP drink wine

$[-$ definite $][-$-specific $]$

'They have drunk wine.'

'Ils ont bu du vin.'(French)

(10) Ena diven dan frizider.

have wine in fridge

[-definite $[+$ specific $]$

'There is wine in the fridge.'

'Il y a du vin dans le frigo.'

(11) Diven dan frizider. wine in fridge

[+definite $[+$ specific $]$

'The wine is in the fridge.'

'Le vin est dans le frigo.'

(French)

Unlike common count nouns in MC, mass nouns can be [+definite, + specific] in subject position without the specificity marker. The different distribution of these two categories of nouns is attributed to the number feature of count nouns, which must be checked. This is an operation that changes the feature specification of the noun from [+arg, - pred] to [-arg, + pred]. A similar process is attested in English where all categories of nouns except singular count nouns can occur in argument positions without D. Given space limitations, I discuss the distribution of only count and mass nouns (not abstract and proper nouns) in my analysis of the determiner systems of English, French, and MC.

\section{SEMANTIC DEFINITIONS AND FUNCTIONS OF DETERMINERS}

Definiteness and specificity are assumed to be distinct categories of meaning that must find expression in natural language; that is, speakers of all languages are sensitive to these categories, even though they may not be morphologically marked in their language. Both definite and indefinite noun phrases can be specific or nonspecific, and these contrasts are explained in terms of denotation and reference.

\subsection{Denotation and reference}

In their base denotation, nouns can denote kinds or properties, but as such they cannot refer. Noun phrases can also serve to denote as in the generic sentences below, where a bird, the bird, and blue birds denote kinds of animals, but these noun phrases fail to refer to any specific instance(s) of birds: 
(12) Denoting expressions:

a. This animal is a bird.

[-definite $[$-specific $]$

b. The bird is a warm-blooded vertebrate.

$[+$ definite $][-$ specific $]$

Referring expressions, on the other hand, point to entities that exist in the world of discourse. In episodic contexts, stage-level predicates select instances of the kind (Carlson 1978), and the subjects of these sentences have a presupposition of existence:

(13) Referring expressions:

a. A bird just flew in.

[-definite $][+$ specific $]$

b. The bird is hungry.

$[+$ definite $][+$ specific $]$

Denoting noun phrases are non-specific, and referring expressions are specific, and both definite and indefinite noun phrases can be $[ \pm$ specific $]$, as shown in the above examples.

\subsection{Definiteness}

An indefinite article is used to introduce into the discourse a new referent, known only to the speaker. A definite article can be used in ensuing discourse on the grounds that the referent is now "familiar" to all speech participants. However, it is not the case that all definite expressions have discourse antecedents. The "familiarity" effect can be licensed by the general knowledge shared by discourse participants, as in the case of unique entities such as the sun, the moon, and the president of the US, where a definite article is required even with the first mention of the referent.

The definite article has been analysed as an operator that binds NP variables (Hawkins 1978; Russell 1905; Stowell 1991; Longobardi 1994, 1996, 2001). The definite article in English quantifies over sets of $\mathrm{N}$ that the hearer must be able to uniquely identify for clear interpretation. ${ }^{3}$ Set membership is equal to one in the case of the singular, and greater than one in the case of the plural. The uniqueness feature of definite descriptions proposed by Russell (1905) thus relates to the set, and not to the individuals therein (which can explain why the definite article in English — unlike the French definite article — does not inflect for number).

Strawson (1950) and Donnellan (1966) differentiate between two main uses of definite descriptions: the attributive (or denoting) use, and the referential (or identifying) use. When a definite description is used referentially, there is a presupposition or implication that a particular someone or something fits the description and that the audience can pick out or think of the right type of person or thing that fits that description: "No such presupposition is present in the attributive use of definite descriptions" (Donnellan 1966:289).

\footnotetext{
${ }^{3}$ I specify "in English" because the definite article in French will be shown in section 4 to have a different function.
} 
Definite noun phrases can serve to denote or to refer, but this distinction is not marked in English and French, where the same article is used whether the expression serves to denote or to refer. In MC, which lacks an overt definite article, the specificity marker $(l a)$ is required when a singular noun phrase is both definite and specific, as shown in (15), where the book, du livre, and liv la all point back to a familiar referent, previously introduced in the discourse:

(14) Fred was discussing an interesting book in his class. (Hawkins 1978:86) Fred ti pe diskit enn liv interesan dan so klas. (MC)

Fred PAST ASP discuss a book interesting in 3SG.POSS class

'Fred discutait d'un livre intéressant dans sa classe.'

(15) I went to discuss the book with him afterwards.

(Hawkins 1978:86)

Mo 'n al diskit liv la ek li apre.

1SG ASP go discuss book SP with 3SG afterwards

'J'ai été discuter du livre avec lui après.' 4

Noun phrases that are referentially anchored to a pre-established discourse referent are specific (Pesetsky 1987, Ishane and Puskás 2001, von Heusinger 2002), and not all definites are necessarily specific, as claimed by Enç (1991).

\subsection{Specificity}

Specificity has more commonly been analysed as a feature of indefinites, despite the fact that definites can also be $[ \pm$ specific $]$. In English, French, and MC, the indefinite article is ambiguous between [ \pm specific] readings when indefinites occur as complements of opacity-inducing predicates, such as intensional transitive verbs, or when they are in the scope of negation. However, in all three languages the proximate demonstrative can be used with specific indefinites, as shown in (17). In the case of the non-specific indefinite, there is no presupposition of existence, while the specific entity is assumed to exist in the world of discourse:

(16) $[-$ definite $][-$ specific $]$

Fred wants to eat a ripe mango. He will look for one on the tree.

Fred ule manz enn mang mir. Li pu rod enn lor pye.

Fred want eat a mango ripe 3SG MOD look.for one on tree

'Fred veut manger une mangue mûre. Il va chercher une sur l'arbre.'

(French)

WANT(f)[RIPE MANGO(x) \& EAT(f, x)]

\footnotetext{
${ }^{4}$ Where $d u$ is a conflation of the preposition $d e$ 'of' and the definite article le.
} 
(17) $[$-definite $][+$ specific $]$

Fred wants to eat $[\mathbf{a} / \text { this ripe mango }]_{\mathrm{i}}$. He saw $\mathbf{i t}_{\mathrm{i}}$ on the tree.

Fred ule manz $[\text { enn mang mir/sa mang mir la }]_{i}$ (MC)

Fred want eat a mango ripe/DEM mango ripe SP

Li 'nn truv $\mathbf{l i}_{\mathrm{i}}$ lor pye. ${ }^{5}$

3SG ASP see it on tree

'Fred veut manger [une/cette mangue mûre $]_{\mathrm{i}}$. Il l li'a vue sur l'arbre.'

(French)

$\exists x[$ RIPE MANGO(x) \& WANT TO EAT(f, $x)]$

The formal representation in the last line of each example shows how the predicate has wide scope in the case of the non-specific reading, and the indefinite NP has wide scope in the case of the specific interpretation.

While the indefinite article in all three languages can be ambiguous with respect to specificity, as shown in examples (16) and (17), indefinite this is unambiguously specific (Prince 1981:233; see also Perlman 1969), as are the French and MC equivalents, namely ce/cet(te) and MC $s a$... la respectively. ${ }^{6}$ Indefinite this, and the French and MC equivalents, cannot be used in the case of non-specific noun phrases as shown by the oddity of (18). Given its presupposition of existence, a specific entity cannot be co-indexed with an indefinite pronoun:

(18) ${ }^{*}$ Fred wants to eat [this ripe mango $]_{i}$. He will look for one $\mathrm{i}_{\mathrm{i}}$ on the tree.

*Fred anvi manz [sa mang mir la] $]_{i}$ Li pu rod enn $n_{\mathrm{i}}$ lor pye. (MC)

*Fred veut manger [cette mangue mûre] $]_{\mathrm{i}}$. Il va en chercher une $\mathrm{i}_{\mathrm{i}}$ sur

l'arbre. (French)

The non-specific and specific readings correspond to what Quine (1960) terms "opaque" and "transparent" readings respectively. A specific noun phrase refers to a particular referent that exists in the world of discourse, while a non-specific noun phrase simply denotes a class of objects, and by extension may refer to any entity fitting the description denoted by the NP, but does not presuppose the existence of that entity.

Specificity encodes deixis. Specific noun phrases serve to point back or forward to discourse referents. Noun phrases that are both definite and specific serve an anaphoric function, as in (15), where 'the book' refers back to a previously introduced discourse referent. Indefinite specific noun phrases introduce a referent about which more will be said in the ensuing discourse - that is, they perform a cataphoric function.

\footnotetext{
${ }^{5}$ Note that while MC post-nominal la serves strictly to mark noun phrases that are both definite and specific, the proximate demonstrative $s a$ combined with the post-nominal specificity marker $l a$ can be used with both definites and indefinites, and like English this (French ce, cette), they always mark specificity.

${ }^{6} \mathrm{MC} s a$ is a demonstrative that cannot be used on its own, but must be used in conjunction with post-DP $l a$. The use of $l a$ on its own is used strictly for nouns that are both [+definite] and [+specific], while $s a+N+l a$ can be $[ \pm$ definite] but it is always $[+$ specific $]$.
} 
If definite articles are in fact derived from demonstratives (Kramsky 1972, Givon 1979, Diessel 1999, Heine and Kuteva 2006, among others), the process of grammaticalization has bleached them of their deictic features, and their function is now purely quantificational. While there can be no reference without quantification (that is, one must quantify over a set in order to refer to it), there can be quantification without reference, as in generic contexts, where subjects are universally quantified.

The Definiteness Phrase (DefP) and the Specificity Phrase (SpP) will be shown to project at different levels in the syntax of the DP.

\section{SYNTACTIC FRAMEWORK}

In this section the syntactic analysis is presented, along with an explanation of how semantic categories are mapped onto syntactic structure within a categorial grammar framework. I assume familiarity with Chomsky's Minimalist Program $(1995,2001 \mathrm{a}, \mathrm{b})$, which proposes that the syntax of natural language is strictly derivational, and that movement is driven by the checking requirements of heads. Convergent derivations satisfy the principle of Full Interpretation (FI), which stipulates that all operator-variable constructions must be legitimate - that is, there should be no vacuous quantification and no free variables. Two levels of representation are assumed, namely Phonetic Form (PF) and Logical Form (LF), which account for the association of sound with meaning.

This syntactic framework is compatible with a formal semantics approach, which postulates a compositional pairing between the syntax of sentences and their truth conditions, and where only closed propositions, with no free variables, can yield a truth value. The condition that "language does not permit free variables" is assumed to be "a specific application of the UG condition FI" (Chomsky 1995:153). My analysis assumes May's (1985) proposal that derivations do not stop at Spellout, but that there is evidence of quantifier raising $(\mathrm{QR})$ at the abstract level of LF. The phenomenon of QR can explain the availability of semantic interpretation when the feature is not overtly marked, as, for example, in the case of specificity in English and French. Overt movement is driven by morphological requirements, and the feature is phonologically realised. Covert movement is also triggered by featurechecking requirements, but in the case of LF movement, there is no overt morphology. Since Move is a costly operation, LF movement is a manifestation of the economy of derivation and representation, a Minimalist principle.

\subsection{The Determiner Phrase (DP)}

The Determiner Phrase (DP), like the clause, is an articulated structure where feature specifications are realized as independent projections (Abney 1987; Szabolcsi 1987, 1989; Stowell 1989, 1991; Ritter 1992; Longobardi 1994, 2001; Bernstein 2001). A DP is defined as the maximal category projected by the class of determiner elements that head the noun phrase, where intermediate projections include, for example, the Number Phrase (NumP), which projects between DefP and NP and is the locus of Number specification (singular or plural) of a noun phrase (Ritter 1992). 
D has standardly been assumed to be Definiteness, and its maximal projection, the Definiteness Phrase (DefP) to be the "locus of referentiality" (Longobardi 1994, 2001). This claim must be revised given that denoting definites do not refer, and given too that indefinites can also be referential, that is, [+specific]. I have argued elsewhere that the topmost projection in the DP is the Specificity Phrase (SpP), and that its clausal equivalent is the Complementizer Phrase (CP), both of which are associated with the discourse (Topic and Focus in the case of CP) (Guillemin 2011). These various projections are represented in (19). In their base position in N, nouns can denote kinds or properties as proposed by Chierchia (1998). The Number Phrase (NumP) projects for count nouns, which must raise to Num to check their [+count] feature. Indefinite articles and cardinal numerals are merged in [Spec,NumP]. Indefinite quantifiers that can combine with both count and mass nouns are merged in the specifier of the Quantifier Phrase (QP). Since both indefinite and definite expressions can serve to denote or to refer, NumP, QP, and DefP can all raise to $[\mathrm{Spec}, \mathrm{SpP}]$ when they are $[+$ specific $] .^{7}$

\subsection{D-Quantifiers and A-Quantifiers}

Determiners include articles, demonstratives, possessive pronouns, and quantifiers like all, (a) few, many, most, much, no, and so forth. They serve to mark features like definiteness, number, and possession, among others. Articles and quantifiers also function as operators that bind NP variables, and they fall into two categories, weak and strong (Milsark 1979, Barwise and Cooper 1981). Strong determiners convert predicative noun phrases into generalized quantifiers (GQs) that can subsequently function as arguments of predicates (Longobardi 1994, 2001; Stowell 1989). They include the definite article and quantifiers like all, each, every, and no, and they are internal to the noun phrase - they are sources of D-Quantification.

Noun phrases with weak determiners, such as the indefinite article and proportional quantifiers like some, many, a few, are cardinality predicates that lack quantificational force (Milsark 1979). They are variables that get introduced into the discourse (Heim 1983, 1988; Kratzer 1989; Diesing 1992) and require binding by operators external to the noun phrase to function as arguments. The sentential operators that typically bind NP variables include, among others, Tense operators and adverbs of quantification - they are sources of A-quantification.

\footnotetext{
${ }^{7}$ Since NumP and QP are in complementary distribution, they are collapsed for ease of representation.
} 


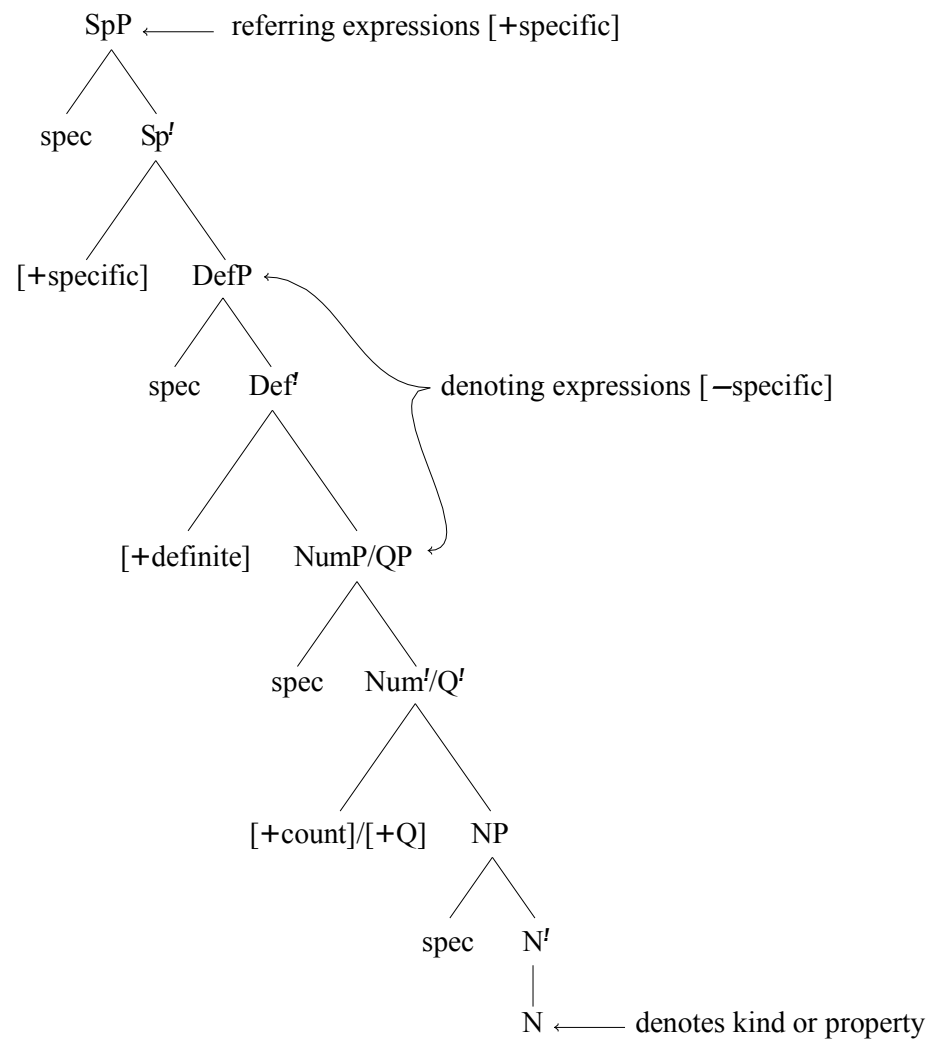

\subsection{Layers in the DP}

My analysis complies with Zamparelli's (2000) "Multi-Layer DP Hypothesis", whereby Strong Determiner Phrases (SDPs) are interpreted in a higher position in the DP, and numerals as Predicative Determiner Phrases (PDPs) in a lower position in DP (2000:5).

The mapping of semantic categories onto syntactic structure is achieved by assuming a categorial grammar framework, where $\mathbf{e}$ is entity (the bearer of reference) and $\mathbf{t}$ stands for the truth value of a sentence, I assume, following Partee (1986), that nominal expressions fall into three categories, namely: (i) $e$ individuals/objects (Pippa, Fred), kinds; (ii) $<\mathrm{e}, \mathrm{t}>$ cardinality predicates (weakly quantified noun phrases); (iii) $<<\mathrm{e}, \mathrm{t}>, \mathrm{t}>$ Generalized Quantifiers (GQs) (strongly quantified noun phrases)

Because they pattern like proper nouns in the grammar, I also assume, following Carlson (1978) and Chierchia (1998), that kinds are of type e. While Zamparelli (2000) takes the denotation of $\mathrm{N}$ in its base position to only denote kinds, I propose that in languages whose nouns are specified as [-arg, +pred], nouns denote properties, that is, they are of type $<\mathrm{e}, \mathrm{t}>$. Furthermore, Zamparelli assigns type $e$ to SDPs, but both DefPs and SpPs are strongly quantified noun phrases; that is, they are GQs of type $<<\mathrm{e}, \mathrm{t}>, \mathrm{t}>$. This is represented in (20), where the following 
hold: (i) the head of the $\mathrm{SpP}$ is realized as $l a$ in $\mathrm{MC}$ and is a null element $(\varnothing)$ in English and French; (ii) the head of the DefP is a phonologically null element in $\mathrm{MC}$, equivalent to English the; (iii) the head of the Number Phrase (NumP), which projects only for common count nouns, is specified as [+count]; indefinite articles, numerals, and the MC plural marker bann are merged in [Spec,NumP]; ${ }^{8}$ (iv) the Quantifier Phrase (QP) and the NumP are in complementary distribution, thus conflated for ease of representation. Indefinite quantifiers such some merge in [Spec, QP].

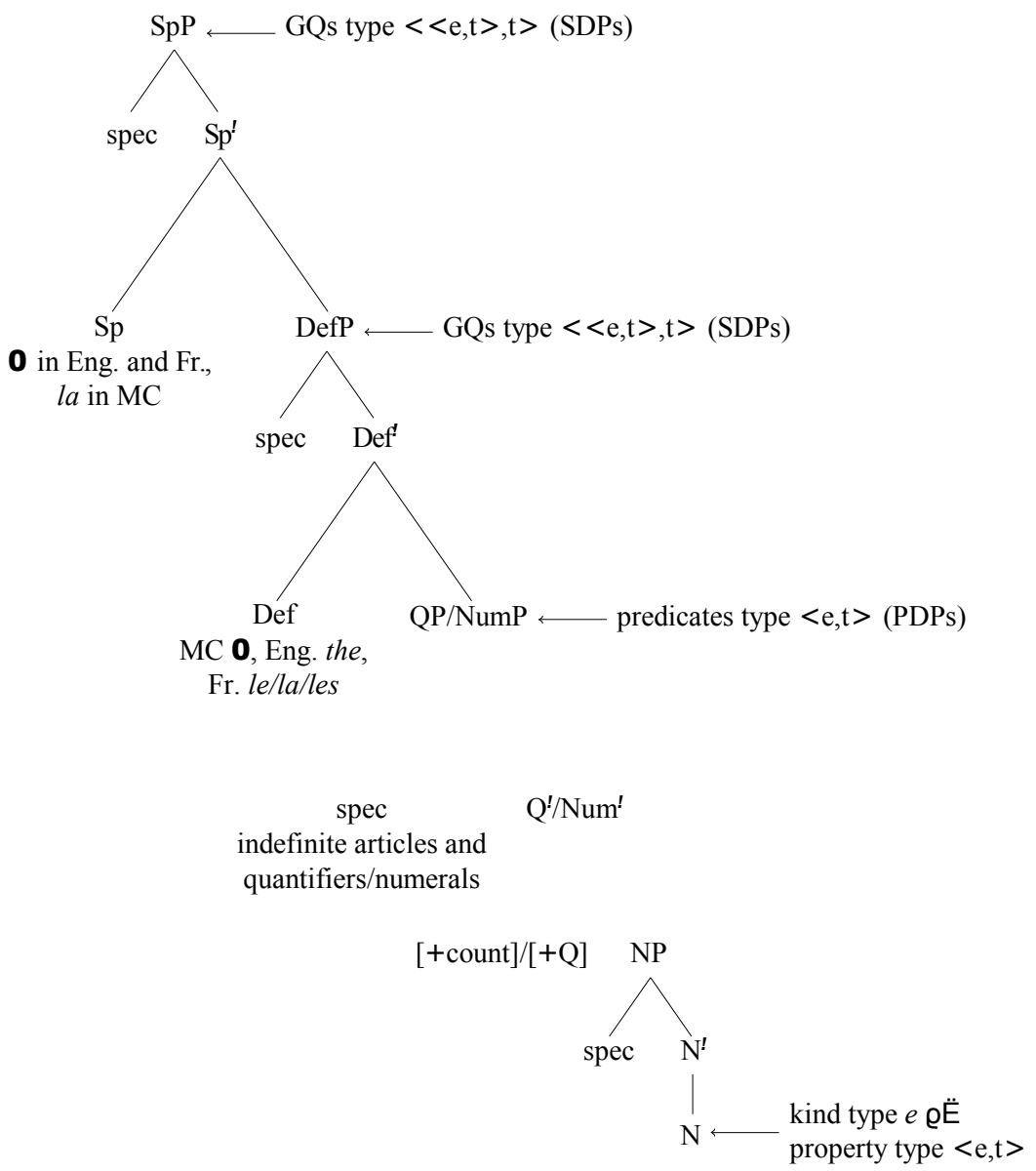

\subsection{MC la licenses an empty category}

Empty categories (ec's) include traces left by movement, as well as phonologically null elements, such as a null definite article, or null copula. Rizzi (1990:74)

${ }^{8}$ The MC plural marker bann is in complementary distribution with numerals, hence assumed to occupy the same position in the DP. 
formulates the Empty Category Principle (ECP), according to which "[a] nonpronominal empty category must be properly head-governed (Formal licensing)". He argues that "one of the core structural relations allowed by UG is head government" (Rizzi 1997:282), which can account for subject-object asymmetries and the licensing of different kinds of ec's. For example, in internal argument positions, a null $\mathrm{D}$ can be licensed by a governing lexical head, such as a verb or preposition, but when there is no overt lexical head, as in subject positions, the specificity marker must project in MC to license the null definite article.

The DP-final position of $l a$ is derived by phrasal movement of DefP to $[\mathrm{Spec}, \mathrm{SpP}]$. Evidence that the whole DefP raises to $[\mathrm{Spec}, \mathrm{SpP}]$ is that $l a$ is always DP-final, regardless of how complex the noun phrase is, as shown in $(21 \mathrm{a}-\mathrm{c})$ :

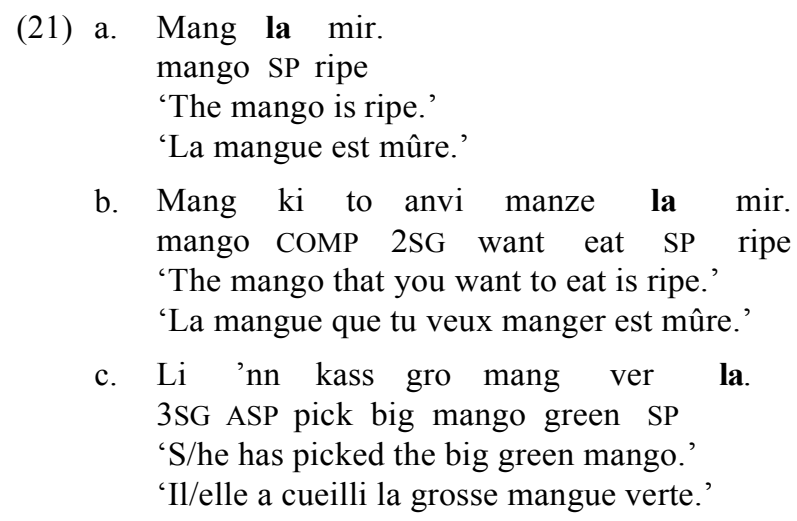

In languages that have overt definite articles, there is no licensing requirement in subject position, and when these DefPs are also [+specific], movement to [Spec, SpP] occurs at LF. This is an instance of $\mathrm{QR}$, and there is no overt marking of the feature $[+$ specific $]$. A Derivation-by-Phase $(\mathrm{DbP})$ analysis can clearly account for the need for an overt specificity marker in the case of definite singular noun phrases in MC.

\subsection{Derivation by Phase}

Chomsky proposes that derivations proceed in "phases" $(\mathrm{PH})$, yielding "propositional" phrases such as the $v \mathrm{P}$ ( $v$ is the causative light verb) and the CP, both of which are semantically and phonologically coherent and independent propositional constructions (Chomsky 2001a,b): "The strong phases are those that have an EPP position as an escape hatch for movement, and are therefore the smallest constructions that qualify for Spell-Out" (Chomsky 2001b:25). Building on previous work relating to the parallel between DPs and CPs (Abney 1987; Szabolcsi 1987, 1989; Stowell 1989, 1991; Ritter 1992; Longobardi 1994, 2001; Bernstein 2001), I assume that the nominal equivalents of $\nu \mathrm{P}$ and $\mathrm{CP}$ are the DefP and the SpP respectively, both of which have an empty specifier position.

The operation TRANSFER, or "Spell-Out", occurs when a PH is "handed over" to the phonological component. Chomsky postulates a Phrase Impenetrability Condition (PIC), according to which, following TRANSFER, only the edge of the 
phase is accessible to further syntactic operations, while the domain of the phasethat is, the complement of the head-becomes inaccessible.

In English and French, the edge of the DefP PH is the overt definite article. In the case of MC common count nouns (that have not raised into Def), the edge of the DefP PH is a phonologically null element $(\varnothing)$, represented as follows:

(22) a. DefP PH in MC $=[\operatorname{DefP}[\operatorname{Def} \varnothing[\mathrm{NP}]]$

b. DefP PH in English and French $=[\operatorname{DefP}[$ Def the/le/la $[\mathrm{NP}]]$

We have seen that the definite article in MC can be licensed by an overt lexical head in internal argument position, where it is governed by a verb or preposition. In subject position, where there is no governor, the specificity marker la projects as a last resort. Within a DbP analysis, this licensing requirement can be formulated as follows:

(23) Licensing ec's within a DbP analysis

a. At least one of two elements that enters into a syntactic operation must be overt.

b. Two ec's cannot enter into a syntactic operation.

The requirement for an overt Specificity marker in the case of [+definite] [+specific] NPs in MC is thus directly attributed to the fact that the definite article is a null element. Both English and French have definite articles that occupy the edge of their DefP PH. The Specificity head in these two languages can be a null element; movement of DefP to [Spec,SpP] can be delayed until LF, and is an instance of QR.

The SpP PH in MC, English, and French is represented in (24), where the head in $\mathrm{MC}$ is $l a$ and the head in English and French is not morphologically realised $(\varnothing)$. Overt movement of DefP to [Spec,SpP] in MC derives the DP-final position of la:

(24) Specific definite $\mathrm{PH}$
a. $\mathrm{SpP} \mathrm{PH}$ in $\mathrm{MC}$

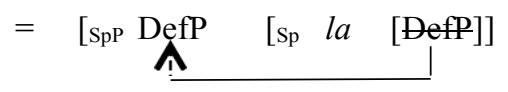

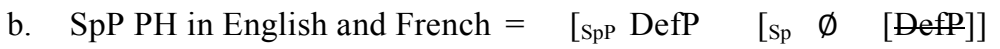

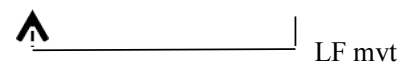

In the case of specific indefinites, there is no overt marking of the feature in $\mathrm{MC}$, as in English and French. The singular indefinite article in all three languages can be ambiguous between [ \pm specific] interpretations (see section 2.2 ). In the case of the non-specific reading (denoting expression), the indefinite is a NumP. In the case of the specific reading, the NumP has raised to [Spec,SpP] at LF:

(25) Specific indefinite PH

$\mathrm{SpP} \mathrm{PH}$ in English, French, and MC $=\quad[\mathrm{spP} \operatorname{NumP}[\mathrm{sp} \emptyset[\mathrm{NumP}]]$

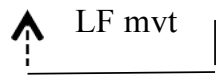


The SpP PH is the nominal equivalent of the CP PH, and phrasal movement of DefP or NumP to [Spec, SpP] is akin to clausal operator movement to [Spec, CP].

\section{TYPE-SHIFTING PRINCIPLES}

Partee (1986) proposes that language makes use of a number of type-shifting devices to derive various categories of noun phrases, namely, $e,<\mathrm{e}, \mathrm{t}\rangle$ and $<<\mathrm{e}, \mathrm{t}\rangle, \mathrm{t}\rangle$. Chierchia (1998:358) also accounts for the different interpretations of bare nouns that occur with stage- and individual-level predicates in terms of a theory of Type Shifting as Last Resort, which he claims is a strategy that UG makes available on demand. The claim that language has type-shifting operators is compatible with Carlson's (1978) insight that the denotation of nouns differs according to whether the predicate is a stage- or an individual-level predicate. The former selects the existential reading of a noun (instances of the kind), and the latter selects the kind reading. For example, a kind-denoting term can be lowered into a predicate or lifted into a GQ, as shown.

\section{(26) a. Cats purr-Kind denoting, Type $e$ \\ b. These creatures are cats-Predicate, Type $<\mathrm{e}, \mathrm{t}>$ \\ c. Cats are purring-GQ, Type $<<\mathrm{e}, \mathrm{t}>, \mathrm{t}>$}

Chierchia (1998) claims that existential quantification over instances of the kind is an automatic, local adjustment triggered by a type mismatch when a kinddenoting noun occurs in an episodic context, with a stage-level predicate. He posits a Nominalizing function, represented as the "down operator" $\cap$ and its inverse, the

Individualizing function, represented as the "up operator" $U$, as follows: (i) If DOG is the property of being a dog, then let DOG be the corresponding kind; (ii) Conversely, if $\mathrm{d}$ is the dog-kind, let $U_{\mathrm{dog}}$ be the property DOG of being a dog (Chierchia 1998:349). These two functions allow us to map properties onto kinds and vice versa, and these options are available, in some form or other, in every language.

Partee (1986:126) proposes that determiners are the obvious candidates for mapping functions, as this is exactly their type: "Natural language data suggest that $a$ (and plural some) and the are particularly natural, since they are often not expressed by a separate word or morpheme but by constructional features, or not expressed at all". Furthermore, she proposes that "in languages lacking an overt definite article, one would have to look for grounds for choosing between a syncategorematic treatment and the positing of a zero definite article" (Partee 1986:123-124).

The definite article in MC is analysed as a "zero" article $(\varnothing)$, equivalent to English the. Both function as strong determiners that quantify over sets of predicative NPs and convert them into GQs. The object of my inquiry is to determine the form and function of the definite article in English, French, and MC, as well as the nature of other D-Quantifiers and A-Quantifiers that trigger type shifting to yield denoting and referring expressions. I aim also to establish if the basic denotation of nouns in these languages is correlated with the differences in their determiner systems. 
Before discussing how types are derived in English, French, and MC, I present tables of how some determiners mark definiteness and specificity in English, French, and MC.

Table 1: Marking [ \pm definiteness $]$ and $[ \pm$ specificity] on count nouns in English, French, and $\mathrm{MC}^{9}$

\begin{tabular}{|c|c|c|c|c|c|}
\hline & & $\begin{array}{l}{[- \text { definite }]} \\
{[- \text { specific] }}\end{array}$ & $\begin{array}{l}{[- \text { definite }]} \\
{[+ \text { specific }]}\end{array}$ & $\begin{array}{l}\text { [+definite] } \\
{[- \text { specific] }}\end{array}$ & $\begin{array}{l}{[+ \text { definite }]} \\
{[+ \text { specific }]}\end{array}$ \\
\hline \multirow{3}{*}{ SG } & English & $a / a n+\mathrm{N}$ & $\begin{array}{l}\text { alan }+\mathrm{N} \\
\text { this }+\mathrm{N}\end{array}$ & the $+\mathrm{N}$ & the $+\mathrm{N}$ \\
\hline & French & un/une + N & $\begin{array}{l}\text { un/une }+\mathrm{N} \\
\text { ce/cet/cette }+\mathrm{N}\end{array}$ & $l e / l a+\mathrm{N}$ & $l e / l a+\mathrm{N}$ \\
\hline & MC & $e n n+\mathrm{N}$ & $\begin{array}{l}e n n+\mathrm{N} \\
s a+\mathrm{N}+\mathrm{la}\end{array}$ & $\begin{array}{l}\mathrm{N} \\
\varnothing+\mathrm{N}\end{array}$ & $\begin{array}{l}\mathrm{N} \\
\varnothing+\mathrm{N}+\mathrm{la} \\
s a+\mathrm{N}+\mathrm{la}\end{array}$ \\
\hline \multirow{3}{*}{ PL } & English & PL N & $\begin{array}{l}\text { some + PL N } \\
\text { these + PL N }\end{array}$ & the + PL N & the + PL N \\
\hline & French & $d e s+$ PL N & $d e s+$ PL N & $l e s+$ PL N & $l e s+$ PL N \\
\hline & MC & $\mathrm{N}$ & $\begin{array}{l}\text { bann }+\mathrm{N} \\
\text { sabann }+\mathrm{N}+l a\end{array}$ & bann $+\mathrm{N}$ & $\begin{array}{l}\text { bann }+\mathrm{N} \\
(s a)+\text { bann }+ \\
\mathrm{N}+\text { la }\end{array}$ \\
\hline
\end{tabular}

Table 2: Marking [ \pm definiteness $]$ and $[ \pm$ specificity] on mass nouns in English, French, and MC

\begin{tabular}{|c|c|c|c|c|}
\hline Language & $\begin{array}{l}\text { [-definite] } \\
\text { [-specific] }\end{array}$ & $\begin{array}{l}\text { [-definite] } \\
{[+ \text {-specific] }}\end{array}$ & $\begin{array}{l}\text { [+definite] } \\
\text { [-specific] }\end{array}$ & $\begin{array}{l}\text { [+definite }] \\
{[+ \text { specific }]}\end{array}$ \\
\hline English & $\mathrm{N}$ & $\begin{array}{l}\text { some }+\mathrm{N} \\
\text { this }+\mathrm{N}\end{array}$ & the $+\mathrm{N}$ & the $+\mathrm{N}$ \\
\hline $\mathbf{F r}$ & $d u / d e l a+\mathrm{N}$ & $\begin{array}{l}\text { du/de la }+\mathrm{N} \\
\text { ce/cet/cette }+\mathrm{N}\end{array}$ & $l e / l a+\mathrm{N}$ & $\begin{array}{l}\text { le/la+ } \mathrm{N} \\
\text { ce/cet/cette }+\mathrm{N}\end{array}$ \\
\hline MC & $\mathrm{N}$ & $\begin{array}{l}\mathrm{N} \\
s a+\mathrm{N}+l a\end{array}$ & $\mathrm{~N}$ & $\begin{array}{l}\mathrm{N} \\
(s a)+\mathrm{N}+l a\end{array}$ \\
\hline
\end{tabular}

The various type-shifting operators that shift nouns from type kind to property and GQ, and which will be discussed in the sub-sections that follow, are represented in Figure $1 .^{10}$

\footnotetext{
${ }^{9}$ Where $\varnothing$ represents the null definite article and PL N stands for the plural form of the noun.

${ }^{10}$ Figure 1 is adapted from Partee (1986) and Chierchia (1998). I disagree with some of their interpretations, and present my arguments against their analysis in the Appendix.
} 


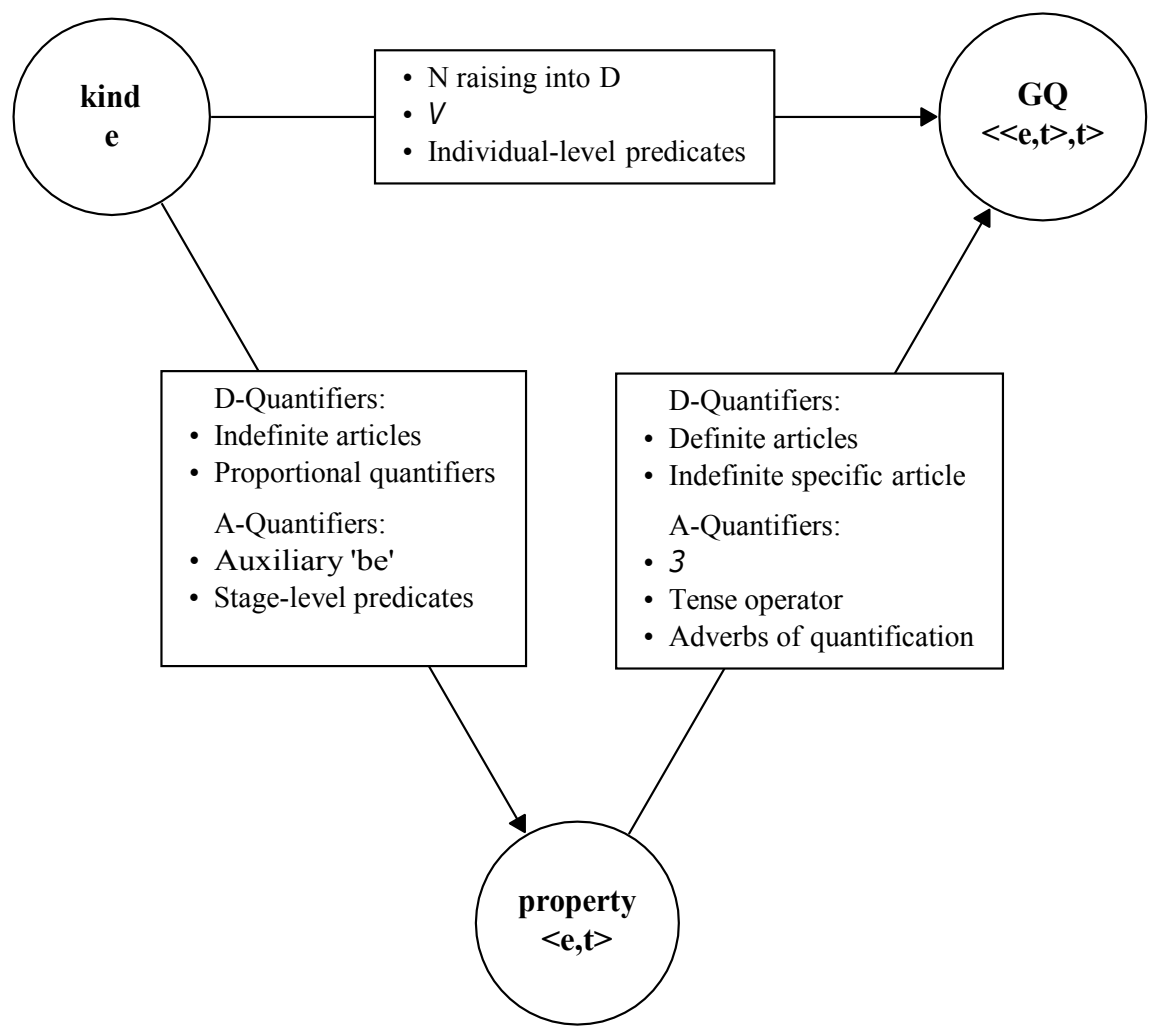

Figure 1: Type-shifting operators in English, French, and MC

The type shift from $e$ to $<<\mathrm{e}, \mathrm{t}>, \mathrm{t}>$ is available for common nouns in English and $\mathrm{MC}$, but not so in French.

The shift from type $e$ to type $\langle\langle\mathrm{e}, \mathrm{t}\rangle, \mathrm{t}\rangle$ applies in English to bare plurals and mass nouns, and in $\mathrm{MC}$ to all count and mass nouns in generic contexts. The individual-level predicate selects a kind as subject, and the operator that converts kinds into GQs is the universal quantifier $\forall$. In syntactic terms, this amounts to $\mathrm{N}$ to Def raising, which is possible in English and MC, since their nouns are specified as [+arg, - pred]. Thus, despite the lack of an overt article, these bare nouns are DPs, not NPs as proposed by Chierchia (1998). This type-shifting operation is not available for common nouns in French, since their basic denotation is that of property (except for some proper nouns):

(27) Count nouns

Dodo napli existe.

dodo NEG exist

'Dodos are extinct.'

*'Dodo n'existe plus.'

(French) 
(28) Mass nouns

Lor kut ser.

$(\mathrm{MC})$

gold cost dear

'Gold is expensive.'

*'Or coûte cher.'

(French)

In $\mathrm{MC}$, common count nouns that have a unique denotation can also be "lifted" (Partee's 1986 term) into a GQ type, but not so in English, which requires a determiner with all singular count nouns:

(29) Unique nouns

Later turn otur soley.

(MC)

earth revolve around sun

*'Earth revolves around sun.'

*'Terre tourne autour soleil.'

(French)

Let's now turn to the type shift from $e$ to $<e, t>$. This type-shifting operation applies in English and MC when $\mathrm{N}$ raises into Num or Q to combine with an indefinite article or numeral (in the case of count nouns), or with a proportional quantifier (in the case of count and mass nouns), thereby creating instances or subsets of $\mathrm{N}$ :

(30) Count noun

Mo ule enn sat / trwa sat / detrwa sat.

$1 \mathrm{SG}$ want a cat three cat some cat

'I would like a cat / three cats / some cats.'

'Je veux un chat / trois chats / quelques chats.'

(French)

(31) Mass noun

Nou ti bwar inpe diven.

$(\mathrm{MC})$

1PL PAST drink some wine

'We drank some wine.'

'Nous avons bu du vin /un peu de vin.'

(French)

Indefinite articles in French do not trigger a type shift, since the nouns are already predicative.

Another operator which type-shifts nouns from $e$ to $\langle e, t\rangle$ is the auxiliary. It mediates between the subject and the predicate in non-verbal predicative constructions, and hosts tense and agreement features. MC lacks an auxiliary equivalent to 'be' (Fr. être), and bare nouns in the creole can never be predicative, as shown in (32) and (33), except for those that denote a role or profession, as in (34):

(32)

* Sa bann zanimo la sat.

$(\mathrm{MC})$

DEM PL animal SP cat

'These animals are cats.' 
(33) Mass noun

* Sa flak la diven.

(MC)

DEM puddle SP wine.

'This puddle is wine.'

MC patterns like French in that the only bare nouns that function as predicates are terms that denote a role or profession, except that in the case of $\mathrm{MC}$, subject and predicate are string-adjacent:

Fred peser / profeser / bankye.
Fred fisherman teacher banker
'Fred is *(a) fisherman / teacher / banker.'
'Fred est pêcheur / professeur / banquier.'

$(\mathrm{MC})$

(French)

In this case, the type $e$ noun is being lowered to type $<\mathrm{e}, \mathrm{t}>$ in $\mathrm{MC}$, but note that there is no type shifting in the case of the French, where nouns already denote properties. English admits bare plurals in these predicative constructions, but requires an indefinite article with singular nouns.

Chierchia proposes an individualizing function $U$ that changes the denotation of nouns from kinds to properties as in the following examples, where it applies in English to bare plurals and mass nouns, and in MC to all count and mass nouns in episodic contexts:

(35) Count noun

Sat pe kasyet anba lili.

cat ASP hide under bed

'Cats are hiding under the bed.'

(36) Mass noun

Diven inn ranvers lor latab.

wine ASP spill on table

'Wine has spilt on the table.'

The individualizing function $U$ is attributed to the stage-level predicate, which selects instances of the kind. The more felicitous reading for the MC sentence (35) is The cat is hiding under the bed, where sat functions as a unique noun, but the indefinite plural interpretation is also available.

I now turn to cardinality predicates, or weakly quantified noun phrases, and show how they are type-shifted into GQs. The English definite article is an operator that ranges over NP variables and converts them into GQs. These NP variables are predicative noun phrases, that is, NumPs or QPs, which denote instances or subsets of $\mathrm{N}$, as in (37).

(37) a. The child with a red beret.

b. The children who went away.

c. The many mistakes that they made.

d. The three musketeers. 
The definite article in English cannot be used with type $e$ nouns in generic contexts, and, unlike the French plural definite article, it never functions as a universal quantifier.

(38) * 'The dodos are extinct.'

'Les dodos n'existent plus.'

* Bann dodo napli existe. ${ }^{11}$

(French)

PL dodo NEG exist

Sentence (38) is possible only in a situation where the dodos represents a subset of animals. For example, when looking at a picture with dodos and Tasmanian tigers, one could say: "The dodos are extinct, but the tigers have survived". A similar contrastive focus reading is derived in (39), which implies that there are dodos still in existence somewhere else in the world, and that the ones from Mauritius are a subset of the genus dodo.

(39) The dodos from Mauritius are extinct.

When the English definite article is used with a singular term in a generic context, the individual functions as a unique representative of the kind, as in (40).

(40) The dodo is extinct.

Dodo napli existe.

'Le dodo n'existe plus.'

A similar effect can be observed with the use of the definite article with mass nouns in generic contexts. The never functions as a universal quantifier. For example, sentence (41) implies contrastive focus, where The gold denotes a set of gold objects, as opposed to a set of non-gold objects:

(41) The gold is expensive.

This type-shifting occurs only in French, where the definite article combines directly with property-denoting nouns to yield definite expressions.

While the English definite article is invariable and plurality is marked on the noun (sg. the house/pl. the houses), articles in French are the locus of number and gender marking. French nouns also inflect for number, but the plural morpheme $-s$ is often not phonologically realized (sg. la maison /lamezõ/, pl. les maisons /lemezõ/).

The fact that number is marked on the articles in French may suggest that count nouns do not need to check their number feature in NumP, as in the case of English and MC nouns. French nouns are already of type $<\mathrm{e}, \mathrm{t}>$ and can combine directly with a definite article to yield GQs. The definite articles in French function like quantified expressions specified for phi features: -le is masculine singular, $l a$ is

\footnotetext{
${ }^{11}$ In MC, a noun phrase marked by the plural bann gives a definite interpretation in subject position. For a detailed analysis of the syntax of MC determiners, see Guillemin (2011), chapter 8 .
} 
feminine singular, and les is masculine or feminine plural. They have an equivalent meaning to 'the one(s)', which makes it possible for them to combine directly with adjectives:

$$
\text { bleu / la }
$$

bleu-e / les bleu(-e)-s

DEF.MASC.SG blue DEF.FEM.SG blue-FEM DEF.PL BLUE(-FEM)-PL 'the blue one / the blue ones.' (= the one(s) that has/have the property of being blue)

The definite article in French combines with all categories of nouns (except for some proper names that are of type $e$ ), and it performs a very different function from English the. While the English definite article is an operator that quantifies over sets, the French definite articles are quantified expressions (not operators) that must be saturated by a property.

Both the singular and plural French definite articles can occur in generic contexts, and the singular article combines with both count and mass nouns:

(43) Count noun

a. Le dodo n' existe plus. the dodo NEG exist more

'The dodo is extinct.'

Dodo napli existe.

b. Les dodos n' existent plus.

DEF.PL dodo NEG exist more

*'The dodos are extinct.'

*Bann dodo napli existe.

The definite article in French also combines with mass nouns in generic contexts, whereas both English and MC use bare nouns:

(44) Mass noun

L'or coûte cher.

Lor kout ser.

gold cost expensive

'Gold is expensive.'

In generic contexts, the French definite article functions as a universal quantifier-les selects the totality of count nouns, and le/la select the totality of mass nouns. In this respect, it is quite different from the definite articles in English and MC, which only quantify over sets.

We saw in section 2.2 that in all three languages the proximate demonstrative (this, Fr. ce/cet(te), MC sa ... la) can combine with all categories of nouns, which they mark as indefinite and specific. These specific noun phrases refer to subsets of $\mathrm{N}$; consequently, they must raise to NumP (in the case of count nouns) or QP (in the 
case of mass nouns). The article selects a NumP or QP, which raises to [Spec,SpP] at LF. ${ }^{12}$

The indefinite specific article serves a cataphoric function; that is, it introduces a new referent that will be a topic of ensuing discourse:

(45) I met this man yesterday. He was quite odd.

Mo ti rankontre sa zom la yer. Li ti inpe drol.

1SG PAST meet DEM man SP yesterday 3SG PAST a.little odd

(MC)

'J'ai rencontré cet homme hier. Il était assez bizarre.'

Indefinites are weakly quantified noun phrases, defined as variables that get introduced into the discourse (Heim 1983, 1988; Kratzer 1989; Diesing 1992), and which require external sources of quantification to convert them into GQs. One such source of A-Quantification is the existential quantifier $\exists$. In existential sentences, which admit only indefinites, the function of 'there be' is to assign existential quantification over the noun phrase (Milsark 1979). It serves to assert the existence of an entity, or some entities that exist in the world of discourse, and triggers a type shift of the noun phrase from $<\mathrm{e}, \mathrm{t}>$ to $<<\mathrm{e}, \mathrm{t}>, \mathrm{t}>$ in all three languages. This is an instance of QR at LF, and there is no marking of the feature [+specific]:

(46) There's a cat on the roof.

Ena enn sat lor twa.

have a cat on roof

'Il y a un chat sur le toit.

(47) There are some cats on the roof.

Ena bann sat lor twa.

have PL cat on roof

'Il y a des chats sur le toit.'

(French)

(48) There's some water in the jug.

Ena inpe dilo dan vaz.

have some water in jug

'Il y a de l'eau dans le vase.'

(French)

In English and MC, bare nouns can occur in existential sentences, as in (49).

(49) a. There are cats on the roof

Ena sat lor twa.

have cat on roof b. There is water in the jug

Ena dilo dan vaz. have water in jug

\footnotetext{
${ }^{12}$ I leave it for future research to determine if the indefinite specific article is merged in $[\mathrm{Spec}, \mathrm{SpP}]$, or if it is in the specifier of a Demonstrative Phrase (DemP) that raises to $[\mathrm{Spec}, \mathrm{SpP}]$ at LF.
} 
Since existential sentences admit only indefinites, these bare nouns can only be interpreted as cardinality predicates, that is, as instances of the kind, of unspecified number or quantity.

A tense operator is present only in episodic contexts, that is, with stage-level predicates, which trigger a stage-level interpretation of their subject (instances of the kind). The English examples in (50a-b) (from Bickerton 1981:130) illustrate how a tense operator changes a denoting expression into a referring expression:

(50) a. When you see a dog are you frightened?

Kan to truv enn lisyen to gagny per?

when 2SG see a dog 2SG have fear 'As-

tu peur quand tu vois un chien?' (French)

b. When you saw a dog were you frightened?

Kan to ti truv enn lisyen to 'nn gagny per? (MC)

when 2SG PAST see a dog 2SG ASP have fear

'As-tu eu peur quand tu as vu un chien?' (French)

Though (50b) can be interpreted as "habitual" in the past, where the subject is nonspecific, the specific reading is only available when the tense operator is present.

Other sources of A-Quantification include adverbs, which yield a specific interpretation of the indefinite, as in (51) where reference is being made to a specific cat. Without the adverb, 'a cat' would simply denote an animal having the property of being a cat.

(51) A cat often comes at night.

Suvan enn sat vini aswar.

often a cat come at.night

'Un chat vient souvent le soir.'

(French)

\section{CONCLUSION}

In this paper I have looked at the various means of quantification that are used in English, French, and MC to derive denoting and referring expressions, that is, both [ \pm definite] and $[ \pm$ specific] noun phrases. My analysis supports Chierchia's (1998) theory according to which the denotation of nouns varies cross-linguistically with respect to the features $[ \pm \mathrm{arg}, \pm$ pred] and that this semantic variation is responsible for the differences in determiner systems. However, I depart from Chierchia's (1998) account in my analysis of English bare plurals as DPs rather than NPs, despite the lack of an overt definite article. When bare plurals and other kinddenoting nouns function as arguments, they are universally quantified nouns that raise into Def, a move made possible by their [+arg, -pred] features.

Whereas Chierchia proposes that English has a mixed system (this would surely complicate language acquisition), a comparison with MC suggests that, as in the creole, all English nouns are specified as [+arg, - pred], and the reason that singular count nouns require a determiner is that they must raise to Num to check their [+count] feature, a move that converts $\mathrm{N}$ from type $e$ to type $\langle\mathrm{e}, \mathrm{t}\rangle$.

A similar pattern is observed in $\mathrm{MC}$, where all categories of nouns can occur 
without a determiner, except for definite singular count nouns, which require the specificity marker in subject positions. I claimed that $\mathrm{MC}$ has a null definite article, which performs a similar function to English the: both quantify over sets of N (i.e., they select NumPs and QPs). Evidence for this empty category comes from subjectobject asymmetry, and the last-resort projection of a specificity marker to license this ec in subject position.

English bare plurals denote kinds (Carlson 1977) but, despite the presence of plural morphology, they are not necessarily specified for number, and "a question like Are there holes in the wall? is truly answerable with Yes under the circumstance where just one hole is in the wall and no more. If this is so, it argues that BPs are not indefinite plurals that stand in contrast to the indefinite singular, but rather forms that instead encompass both" (Carlson 1999:4). According to Carlson (1977) the plural of the indefinite article a/an is some and not a null determiner. It could thus well be that, in English, the base denotation of $\mathrm{N}$ is plural in the sense that it encompasses the totality of Ns in the world. In a generic context, an MC bare noun translates into an English BP, the difference between the two languages being the availability of plural morphology in English, which is lacking in MC.

Another significant difference between English and MC is the fact that English has an overt definite article, while this operator is a null element in MC. Given the availability of the, Chierchia (1998:360) notes that: "Language-particular choices win over universal tendencies" (cf. the "Elsewhere Condition"), or "Don't do covertly what you can do overtly". This option is not available in MC, where speakers have to resort to other type-shifting operations that Universal Grammar makes available, such as Chierchia's abstract Nominalizing and Individualizing functions, which have been shown to be attributed to various A-Quantifiers and DQuantifiers.

My analysis of type-shifting operators has also shed light on the different functions of the English and French definite articles. While the former is an operator that quantifies over sets of $\mathrm{N}$, the French article functions like a quantified expression specified for number and gender, and which selects a property-denoting N. In generic contexts, the French plural definite article is equivalent to a universal quantifier $\forall$, a function that is not available to the definite articles in English and MC.

This paper represents part of an ongoing inquiry into the marking of definiteness and specificity cross-linguistically, as well as the sources of quantification that trigger the various interpretations of bare nouns. Elsewhere (Guillemin 2014), I have argued that languages that mark the [ \pm definite] contrast, such as English and French, need not necessarily mark the [ \pm specificity] contrast. Within a Derivation-by-Phase analysis I have proposed herein that the specificity marker la in $\mathrm{MC}$ is a morphosyntactic element needed to license the null definite article. There is no such requirement in English and French, both of which have overt definite articles. Such a claim warrants further research into the form and function of these semantic categories cross-linguistically, and especially how they are marked in other languages with and without articles. 


\section{REFERENCES}

Abney, Steven P. 1987. The English noun phrase and its sentential aspect. Doctoral dissertation, Massachusetts Institute of Technology.

Barwise, Jon and Robin Cooper. 1981. Generalized quantifiers and natural language. Linguistics and Philosophy 4:159-219.

Bernstein, Judy B. 2001. The DP Hypothesis: Identifying clausal properties in the nominal domain. In The handbook of contemporary syntactic theory, ed. Mark Baltin and Chris Collins, 536-561. Oxford: Blackwell.

Bickerton, Derek. 1981. Roots of language. Ann Arbor, MI: Karoma.

Carlson, Gregory N. 1977. A unified analysis of the English bare plural. Linguistics and Philosophy 1:413-457.

Carlson, Gregory N. 1978. Reference to kinds in English. Bloomington: Indiana University Linguistics Club.

Carlson, Gregory N. 1999. No lack of determination: On determinerless noun phrases. GLOT International 4(3):3-8.

Chierchia, Gennaro. 1998. Reference to kinds across languages. Natural Language Semantics 6:339-405.

Chomsky, Noam. 1995. The Minimalist program. Cambridge, MA: MIT Press.

Chomsky, Noam. 2001a. Beyond explanatory adequacy. MIT Occasional Papers in Linguistics, No. 20, 1-25. Cambridge, MA: Distributed by MIT Working Papers in Linguistics.

Chomsky, Noam. 2001b. Derivation by phase. In Ken Hale: A life in language, ed. Michael Kenstowicz, 1-52. Cambridge, MA: MIT Press.

Diesing, Molly. 1992. Indefinites. Cambridge, MA: MIT Press.

Diessel, Holger. 1999. The morphosyntax of demonstratives in synchrony and diachrony. Linguistic Typology 3:1-49.

Donnellan, Keith S. 1966. Reference and definite descriptions. The Philosophical Review 75:281-304.

Enç, Mürvet. 1991. The semantics of specificity. Linguistic Inquiry 22:1-25.

Givon, Talmy. 1979. On understanding grammar. New York: Academic Press.

Guillemin, Diana. 2011. The syntax and semantics of a determiner system: A case study of Mauritian Creole. Amsterdam: John Benjamins.

Guillemin, Diana. 2014. Marking definiteness or specificity, not necessarily both: Evidence of a principle of economy from Mauritian Creole. In Language description informed by theory, ed. Rob Pensalfini, Myf Turpin, and Diana Guillemin, 193-216. Amsterdam: John Benjamins.

Hawkins, John. 1978. Definiteness and indefiniteness: A study in reference and grammaticality prediction. London: Croom Helm.

Heim, Irene. 1983. File change semantics and the familiarity theory of definiteness. In Meaning, use and interpretation of language, ed. Rainer Bäuerle, Christoph Schwarze, and Arnim von Stechow, 165-189. Berlin: de Gruyter.

Heim, Irene. 1988. The semantics of definite and indefinite noun phrases. New York: Garland.

Heine, Bernd and Tania Kuteva. 2006. The changing languages of Europe. Oxford: Oxford University Press. 
von Heusinger, Klaus. 2002. Specificity and definiteness in sentence and discourse structure. Journal of Semantics 19:245-274.

Himmelmann, Nikolaus P. 2001. Articles. In Language typology and language universals: An international handbook, eds. Martin Haspelmath, Ekkehard König, Wulf Oesterreicher, and Wolfgang Raible, 831-841. Berlin: de Gruyter. Ishane,

Tabea and Genoveva Puskás. 2001. Specific is not definite. Generative Grammar in Geneva 2:39-54.

Krámský, Jiří. 1972. The article and the concept of definiteness in language. The Hague: Mouton.

Kratzer, Angelika. 1989. Stage-level and individual-level predicates. In Papers on quantification, ed. Emmon Bach, Angelika Kratzer, and Barbara Partee. Amherst, MA: Department of Linguistics, University of Massachusetts, Amherst.

Longobardi, Giuseppe. 1994. Reference and proper names: A theory of Nmovement in syntax and Logical Form. Linguistic Inquiry 25:609-665.

Longobardi, Giuseppe. 1996. The syntax of N-raising: A minimalist theory. In OTS Working Papers. Utrecht: Research Institute for Language and Speech, University of Utrecht.

Longobardi, Giuseppe. 2001. The structure of DPs. In The handbook of contemporary syntactic theory, ed. Mark Baltin and Chris Collins, 562-603. Oxford: Blackwell.

May, Robert. 1985. Logical form: Its structure and derivation. Cambridge, MA: MIT Press.

Milsark, Gary. 1979. Existential sentences in English. New York: Garland.

Partee, Barbara H. 1986. Noun Phrase interpretation and type-shifting principles. In Studies in Discourse Representation Theory and the theory of generalized quantifiers, ed. Jeroen Groenendijk, Dick de Jongh, and Martin Stokhof, 115143. Dordrecht: Foris.

Partee, Barbara H. 1992. Adverbial quantification and event structures. In Proceedings of the Seventeenth Annual Meeting of the Berkeley Linguistics Society: Parasession on the Grammar of Event Structures, 439-456. Berkeley Linguistics Society, University of California, Berkeley.

Perlman, Alan. 1969. "This" as a third article in American English. American Speech 44:76-80.

Pesetsky, David. 1987. Wh-in-situ: Movement and unselective binding. In The representation of (in)definiteness, ed. Eric J. Reuland and Alice G. B. ter Meulen, 98-129. Cambridge, MA: MIT Press.

Prince, Ellen F. 1981. On the inferencing of indefinite-this NPs. In Elements of discourse understanding, eds. Aravind K. Joshi, Bonnie L. Webber, and Ivan

A. Sag, 231-250. Cambridge: Cambridge University Press.

Quine, Willard V. 1960. Word and object. Cambridge, MA: MIT Press.

Ritter, Elizabeth. 1992. Cross-linguistic evidence for Number Phrase. Canadian Journal of Linguistics / Revue canadienne de linguistique 37:197-218.

Rizzi, Luigi. 1990. Relativized Minimality. Cambridge, MA: MIT Press.

Rizzi, Luigi. 1997. The fine structure of the left periphery. In Elements of grammar: Handbook in generative syntax, ed. Liliane Haegeman, 281-337. Dordrecht: 
Kluwer.

Russell, Bertrand. 1905. On denoting. Mind 14:479-493.

Stowell, Tim. 1989. Subjects, specifiers, and X-Bar Theory. In Alternative conceptions of phrase structure, ed. Mark Baltin and Anthony S. Kroch, 232262. Chicago: University of Chicago Press.

Stowell, Tim. 1991. Determiners in NP and DP. In Views on phrase structure, ed. Katherine Leffel and Denis Bouchard, 37-56. Dordrecht: Kluwer.

Strawson, Peter Frederick. 1950. On referring. Mind 59:320-344.

Szabolcsi, Anna. 1987. Functional categories in the noun phrase. In Approaches to Hungarian, ed. István Kenesei, 167-189. Szeged: JATE.

Szabolcsi, Anna. 1989. Noun phrases and clauses: Is DP analogous to CP? In The structure of noun phrases, ed. John Payne, 151-180. Berlin: de Gruyter.

Zamparelli, Roberto. 2000. Layers in the determiner phrase. New York: Garland.

\section{ABbreviations}

$\begin{array}{llll}\text { arg } & \text { argumental } & \text { Num } & \text { number } \\ \text { ASP } & \text { aspect } & \text { NumP } & \text { Number Phrase } \\ \text { BP } & \text { Bare Plural } & \text { PDP } & \text { Predicative Determiner Phrase } \\ \text { COP } & \text { copula } & \text { PF } & \text { Phonetic Form } \\ \text { CP } & \text { Complementizer Phrase } & \text { PH } & \text { phase } \\ \text { D } & \text { determiner } & \text { PIC } & \text { Phase Impenetrability Condition } \\ \text { Def } & \text { definite } & \text { PL } & \text { plural } \\ \text { DefP } & \text { Definiteness Phrase } & \text { POSS } & \text { possessive } \\ \text { DEM } & \text { demonstrative } & \text { PRED } & \text { predicative } \\ \text { DP } & \text { Determiner Phrase } & \text { Q } & \text { quantifier } \\ e & \text { entity } & \text { QP } & \text { Quantifier Phrase } \\ \text { ec } & \text { empty category } & \text { QR } & \text { Quantifier Raising } \\ \text { EPP } & \text { Extended Projection Principle } & \text { SDP } & \text { Strong Determiner Phrase } \\ \text { FEM } & \text { feminine } & \text { SG } & \text { singular } \\ \text { FI } & \text { Full Interpretation } & \text { Sp } & \text { specificity } \\ \text { INFL } & \text { inflection } & \text { spec } & \text { specifier } \\ \text { LF } & \text { Logical Form } & \text { SpP } & \text { Specificity Phrase } \\ \text { MASC } & \text { masculine } & \text { UG } & \text { Universal Grammar } \\ \text { MC } & \text { Mauritian Creole } & \text { V } & \text { verb } \\ \text { N } & \text { noun } & v P & \text { (causative light) verb Phrase } \\ \text { NEG } & \text { negation } & \text { t } & \text { truth } \\ \text { NMP } & \text { Nominal Mapping Parameter } & & \\ \text { NP } & \text { Noun Phrase } & & \end{array}$




\section{APPENDIX}

The following diagram, showing the type-shifting operators that shift kinds into properties and GQs and vice versa, is adapted from Partee (1986) and Chierchia (1998):

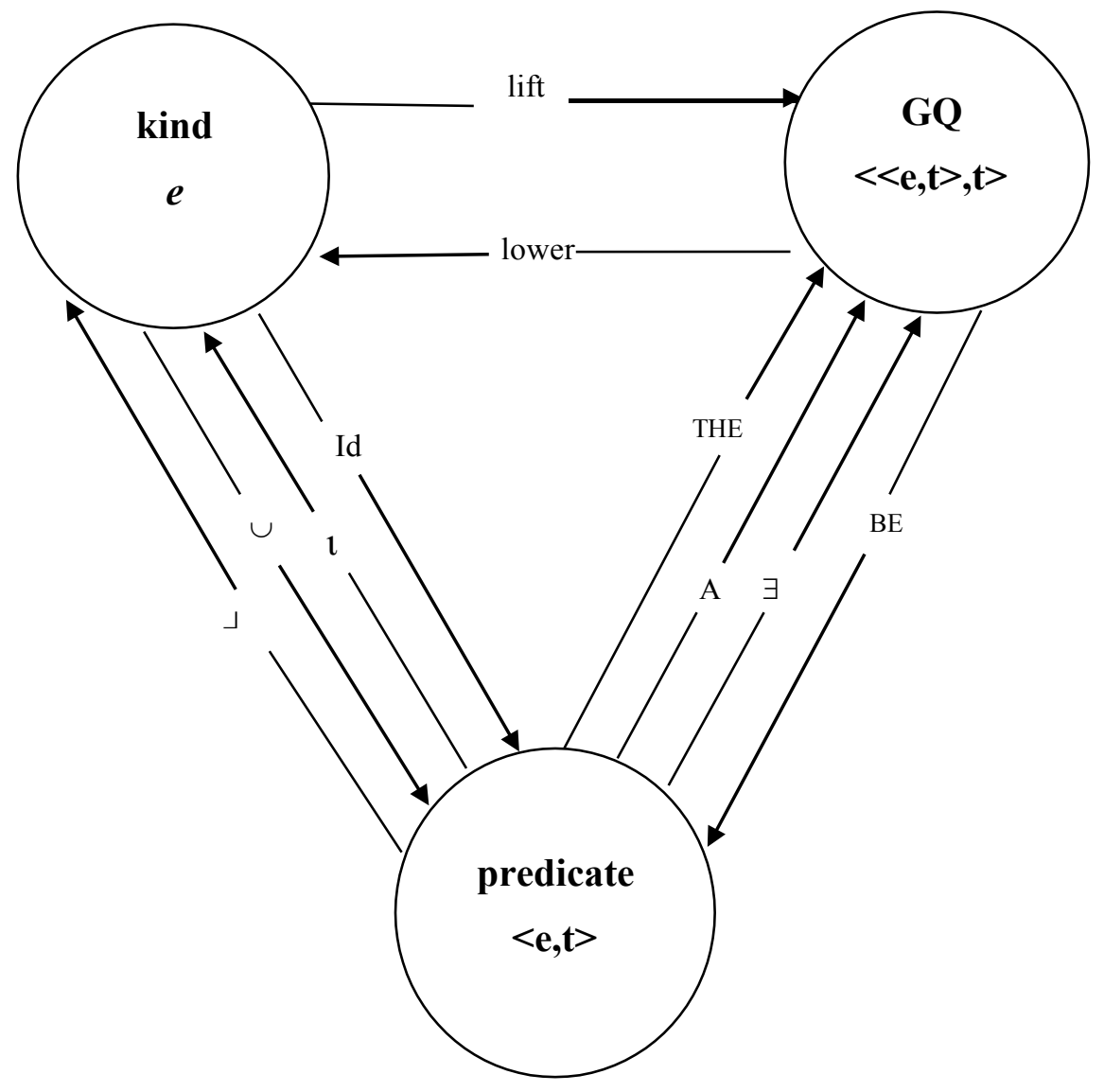

Figure 2: Type-shifting operators 
Figure 2 is adapted from Chierchia's (1998:359) example (25) ${ }^{13}$ and Partee's (1986:121) Diagram 1, where:

- The operation lift converts an individual or kind-denoting noun of type $e$ into a GQ of type $<<\mathrm{e}, \mathrm{t}>, \mathrm{t}>$. This operation would apply in the case of $\mathrm{N}$ raising to $\mathrm{D}$, yielding bare nominal arguments.

- The operation lower applies when a GQ has an $e$ type reading, but Partee (1986:123) suggests that "lower is not necessarily part of the grammar of English at all". This operation is not attested in French or MC either.

- The nominalising function converts predicates into kinds, a change brought about when a predicative NP occurs with individual-level predicates, as in Dogs are barking.

- The individualising function ${ }^{U}$ is the inverse of ${ }^{n}$. It assigns existential quantification over instances of the kind, a change effected when a kinddenoting noun combines with a stage-level predicate, as in Dogs bark.

- The iota operator $\mathbf{l}$ (proposed by Partee) maps any singleton set onto its member. It "selects the greatest element from the extension of a predicate and constitutes typically the meaning of the definite article" (Chierchia 1998:359). It is equivalent to the definite article when used with singular terms.

- The inverse of the 1 -operator, Id (proposed by Partee (1986)), expresses the "part-of" relation. Both $\mathbf{\imath}$ and Id are closely related to Chierchia's and $U$ respectively.

- $\exists$ is "an operation of existential closure, which turns a property into a generalized quantifier. This is traditionally taken to be the meaning of the indefinite article $a$ " (Chierchia 1998:359).

- A (proposed by Partee) is equivalent to the indefinite article. I disagree with Partee's analysis of the indefinite article as a type-shifting operator that converts type <e,t $>$ into a GQ. For example, in the sentence $A \operatorname{dog}$ barks, the nonspecific indefinite $a \operatorname{dog}$ denotes a property, while in the sentence $A d o g$ barked, the specific indefinite refers to an instance of the kind. The change from type $<\mathrm{e}, \mathrm{t}>$ to type $<<\mathrm{e}, \mathrm{t}>, \mathrm{t}>$ is triggered by the tense operator.

- BE converts a GQ into a predicate. I also disagree with Partee's analysis of be as a function that encompasses both auxiliary be, as in (1a), and the be of identity, as in (1b). While tall is a predicate that cannot be inverted with the subject as shown, the noun phrases in (1b) are both quantified DPs:

(1) a. Jack is tall / a fisherman. (*Tall is Jack. / *A fisherman is Jack.)

b. Jack is my brother. (My brother is Jack.)

Unlike auxiliary be, the be of identity takes a subject and a complement and establishes a relation of identity between the two. Subject-complement inversion is

${ }^{13}$ There seems to be a discrepancy in Chierchia's diagram where the direction of the arrows for BE and $\exists$ contradict his explanation of these terms, namely $\exists:<e, t>\rightarrow$ GQ, and BE: $\mathrm{GQ} \rightarrow<\mathrm{e}, \mathrm{t}>$. 
possible, as shown in (1b). MC has a null copula equivalent to auxiliary be and an equative copula se (the be of identity), which cannot be used with predicative noun phrases. The null copula and se are not interchangeable, as shown in (2a-b):

(2) a. Zak $\varnothing \quad$ gran/peser. (*Zac se gran. / *Zac se peser.) Jack COP tall/a fisherman

b. Zac se mo frer. (Mo frer se Zak.)

Jack COP 1SG.POSS brother

Consequently, in my analysis of type-shifting operations, I have analysed be strictly as an auxiliary that mediates between the subject and predicate and hosts tense and agreement features, and not as equative 'be' or the 'be' of identity. 